\title{
Enhanced Wear Resistance of Zr-Based Bulk Metallic Glass by Thermal Oxidation Treatment
}

\author{
Kun Zhou*, Shujie Pang, Chen Chen, Ying Liu, Wei Yang and Tao Zhang \\ Key Laboratory of Aerospace Materials and Performance (Ministry of Education), School of Materials Science and Engineering, Beihang \\ University, Beijing 100191, China
}

Enhancement of surface properties such as wear resistance of Zr-based bulk metallic glasses (BMGs) is important for many applications of the materials. In this paper, the effect of thermal oxidation on the tribological behavior of a $\mathrm{Zr}$-Ti-Cu-Al-Y BMG was studied. It is found that oxidation treatment greatly improves the wear resistance of the BMG, which is ascribed to the formation of a layer of oxidized scale. This result is beneficial for the improvement of surface properties and further application of the Zr-based BMGs. [doi:10.2320/matertrans.M2016356]

(Received November 21, 2016; Accepted December 21, 2016; Published February 25, 2017)

Keywords: bulk metallic glass, oxidation, indentation and hardness, wear and tribology

\section{Introduction}

Zr-based bulk metallic glasses (BMGs) possess excellent glass-forming ability (GFA), high strength and hardness, relatively low elastic modulus, good corrosion resistance, nanoscale imprintability, etc., which enable them to be utilized in many industrial applications such as sporting goods, micro-geared motor parts, pressure sensors and biomedical materials ${ }^{1,2)}$. Surface properties such as wear resistance should be taken into consideration in many engineering applications. The tribological behavior of Zr-based BMGs has been studied extensively ${ }^{3-14)}$, however, the results in different works are controversial. In some cases, Zr-based BMGs show high wear resistance, better than their crystallized counterparts and some conventional engineering alloy such as GCr15 steel $^{5,7)}$, while in some other cases they exhibit no indication of superior tribological properties or even worse wear resistance than commonly used engineering materials like Al6061, 304 SS, 316 L SS and CoCrMo alloy ${ }^{3,4,9,12)}$. It has been reported that the tribological performance of Ti-6Al-4V could be improved by thermal oxidizing treatment ${ }^{15,16}$, however, to the best of our knowledge, there has been no research about the effect of oxidation on the tribological behavior of BMGs. In this study, the tribological behavior of a Ni-free $\left(\mathrm{Zr}_{0.5} \mathrm{Ti}_{0.02} \mathrm{Cu}_{0.38} \mathrm{Al}_{0.1}\right)_{98} \mathrm{Y}_{2}$ (at.\%) BMG before and after oxidation was studied and the results show that the wear resistance of the BMG can be significantly improved by oxidation treatment. The mechanism for the improvement of wear resistance was discussed.

\section{Experimental}

Alloy ingot with nominal composition of $\left(\mathrm{Zr}_{0.5} \mathrm{Ti}_{0.02} \mathrm{Cu}_{0.38} \mathrm{Al}_{0.1}\right)_{98} \mathrm{Y}_{2}$ (at.\%) was prepared by arc melting the mixture of raw materials $\mathrm{Zr}, \mathrm{Ti}, \mathrm{Cu}, \mathrm{Al}$ and $\mathrm{Y}$ under Ti-gettered highly purified argon atmosphere. From the master alloy, plates with dimension of $1.5 \mathrm{~mm} \times 10 \mathrm{~mm} \times 50 \mathrm{~mm}$ were fabricated by copper mold casting. Microstructures of the plates were examined by an X-Ray diffractometer (XRD; $\mathrm{D} / \mathrm{MAX}-2500$ ) with $\mathrm{Cu}-\mathrm{K} \alpha$ radiation.

*Corresponding author, E-mail: azhou176@163.com
The specimens were cut from these plates to a dimension of $1.5 \mathrm{~mm} \times 8 \mathrm{~mm} \times 16 \mathrm{~mm}$ and ground with $\mathrm{SiC}$ sandpaper down to 2000 grit, and then cleaned in acetone. The oxidation was carried out in a tubular furnace at $653 \mathrm{~K}$ (below $T_{\mathrm{g}}$ of the $\mathrm{BMG}^{17)}$ ) and a holding time of $1.5 \mathrm{~h}$ in air atmosphere. After oxidation, the structures of the specimens were characterized by XRD. The morphology of the oxidized specimen was examined by SEM (CamScan 3400).

The tribological behaviors of the as-cast and oxidized $\left(\mathrm{Zr}_{0.5} \mathrm{Ti}_{0.02} \mathrm{Cu}_{0.38} \mathrm{Al}_{0.1}\right)_{98} \mathrm{Y}_{2}$ were tested by ball-on-disc linear reciprocating wear mode on a Universal Micro-Tribotester (UMT-2). $\mathrm{Si}_{3} \mathrm{~N}_{4}$ spheres with a diameter of $4 \mathrm{~mm}$ were used as the counter material. The experiment parameters were set as normal load of $5 \mathrm{~N}$, frequency of $1 \mathrm{~Hz}$, sliding track length of $3 \mathrm{~mm}$ and duration of $0.5 \mathrm{~h}$. After tribological test, the wear scar morphologies of the specimens were observed by SEM and chemical composition analysis was conducted by energy dispersive spectrometer (EDS) attached to SEM. The wear losses and surface roughness were measured by an optical interferometer (Phase Shift MicroXAm-3D). The microhardness $(H)$ and reduced Young's modulus $\left(E_{\mathrm{r}}\right)$ of the specimens were measured by a nanoindenter (Nanoindenter XP).

\section{Results and Discussion}

Figure 1 (a) shows the XRD patterns of the as-cast and oxidized $\left(\mathrm{Zr}_{0.5} \mathrm{Ti}_{0.02} \mathrm{Cu}_{0.38} \mathrm{Al}_{0.1}\right)_{98} \mathrm{Y}_{2}$ specimens. For the as-cast specimen, only a broad diffusion peak for typical amorphous structure without any appreciable Bragg peaks can be seen. After oxidized at $653 \mathrm{~K}, \mathrm{t}-\mathrm{ZrO}_{2}, \mathrm{Al}_{2} \mathrm{O}_{3}$ and $\mathrm{Cu}_{2} \mathrm{O}$ can be identified on the alloy surface while the substrate remains amorphous. Figure 1 (b) shows the backscattered electron image (BEI) of the cross-section of the oxidized specimen, revealing a uniform, well-adherent scale with a thickness of about $4.2 \mu \mathrm{m}$.

The microhardness $(H)$, reduced Young's modulus $\left(E_{\mathrm{r}}\right)$ and the ratio of hardness to reduced Young's modulus $\left(H / E_{\mathrm{r}}\right)$ of the as-cast and oxidized BMGs are listed in Table 1. For the oxidized BMG, $H$ and $E_{r}$ of the substrate slightly increase, while the $H / E_{\mathrm{r}}$ ratio exhibits no significant difference compared with that of the as-cast one. However, the scale on the oxidized BMG exhibits much higher $H$ and $H / E_{\mathrm{r}}$ ratio than 
the substrate and as-cast BMG.

The three-dimensional and two-dimensional profiles of the wear scars after sliding tests are shown in Fig. 2. A deep furrow can be observed on the as-cast specimen in Fig. 2 (a). In contrast, the wear scar is much shallower on the oxidized specimen as can be seen in Fig. 2 (b). The widths and depths of the scars are shown in Fig. 2 (c) and also listed in Table 1. It can be seen that the scar depth is much reduced after the

(a)
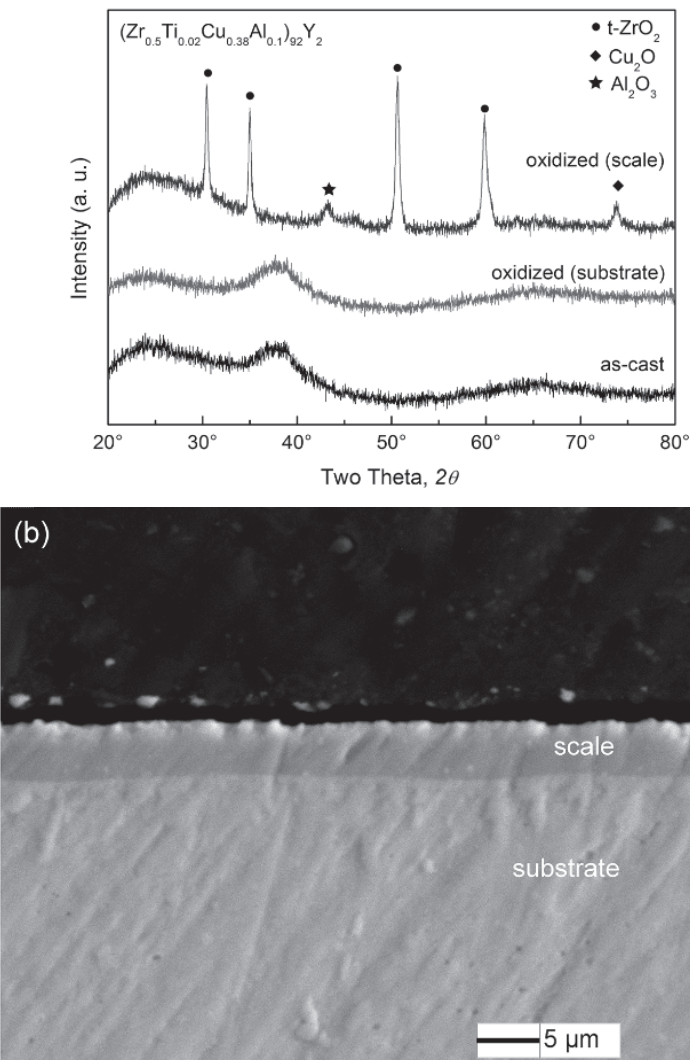

Fig. 1 (a) XRD patterns of the as-cast and oxidized $\left(\mathrm{Zr}_{0.5} \mathrm{Ti}_{0.02} \mathrm{Cu}_{0.38} \mathrm{Al}_{0.1}\right)_{98} \mathrm{Y}_{2}$, (b) the backscattered electron image (BEI) of the cross-section of the oxidized specimen. oxidation treatment. This result indicates that the wear resistance of the BMG can be significantly enhanced by surface oxidation. Besides, the scar depth of the oxidized specimen $(0.217 \mu \mathrm{m})$ is much smaller than the thickness of the oxidized scale $(4.2 \mu \mathrm{m})$, which means that the wear could not penetrate the scale under this condition and the enhancement of wear resistance of the BMG is mainly attributed to the formation of oxidized scale.

Figure 3 (a) and (b) show the SEM images and EDS results of the wear scars on the as-cast and oxidized specimens respectively. As seen in Fig. 3 (a), a number of ploughed grooves are present in the worn surface, which is a typical topography feature of abrasive wear controlled mechanism. The wear scar exhibits two distinct regions (marked by A and $\mathrm{B}$ in Fig. 3 (a)). The EDS results indicate that higher $\mathrm{O}$ and $\mathrm{Si}$ elements exist in region $\mathrm{A}$, in which $\mathrm{Si}$ is transferred from the $\mathrm{Si}_{3} \mathrm{~N}_{4}$ sphere, and $\mathrm{O}$ originated from the oxidation during the wear test. The composition of region B is almost identical with the nominal composition of the Zr-based BMG. This result indicate that surface oxidation happened during the sliding, however, the oxidized scale formed during the sliding process is inhomogeneous. Surface oxidation also took place in some other studies for Zr-based BMGs under dry-sliding tests ${ }^{4,8,14)}$, which may be caused by the high flash temperature generated on the friction surface ${ }^{11,14)}$. In Fig. 3 (b), the oxidized BMG shows a much smoother worn surface than the as-cast one, only some tiny scratches and a few shallow pits can be observed on the scar. The EDS results indicate that the composition of most of the surface area (marked by $\mathrm{C}$ in Fig. 3 (b)) is close to the original composition of the oxidized surface. The small pits (represented by D in Fig. 3 (b)) show slightly higher $\mathrm{O}$ and $\mathrm{Si}$ contents. These pits are probably the original defects on the specimen or caused by the microfragmentation of a small fraction of the scale. Figure 4 shows the SEM images of the surfaces of the $\mathrm{Si}_{3} \mathrm{~N}_{4}$ counter spheres sliding against the as-cast $\mathrm{BMG}$ and oxidized $\mathrm{BMG}$ respectively. In Fig. 4 (a), wear debris (marked by white arrow) can be seen on the surface of the $\mathrm{Si}_{3} \mathrm{~N}_{4}$ sphere after sliding against the as-cast BMG. Corresponding EDS analysis indicates that the wear debris adhered to $\mathrm{Si}_{3} \mathrm{~N}_{4}$ sphere has similar composi-

Table 1 Microhardness; reduced Young's modulus; $H / E_{\mathrm{r}}$; roughness; scar depth and width for the as-cast and oxidized $\left(\mathrm{Zr}_{0.5} \mathrm{Ti}_{0.02} \mathrm{Cu}_{0.38} \mathrm{Al}_{0.1}\right)_{98} \mathrm{Y}_{2} \mathrm{BMG}$.

\begin{tabular}{lccccc}
\hline Specimen & $H(\mathrm{GPa})$ & $E_{\mathrm{r}}(\mathrm{GPa})$ & $H / E_{\mathrm{r}}$ & $R_{\mathrm{a}}(\mathrm{nm})$ & Scar depth $(\mu \mathrm{m})$ \\
\hline as-cast BMG & 6.540 & 118.328 & 0.055 & 153 & 12.2 \\
oxidized BMG (scale) & 11.341 & 181.825 & 0.062 & 150 & 0.217 \\
oxidized BMG (substrate) & 6.625 & 120.934 & 0.055 & - & - \\
\hline
\end{tabular}

(a)

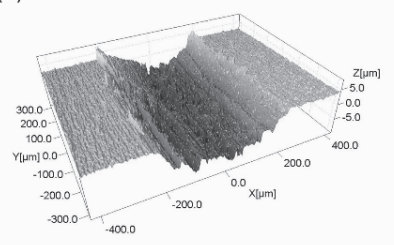

(b)

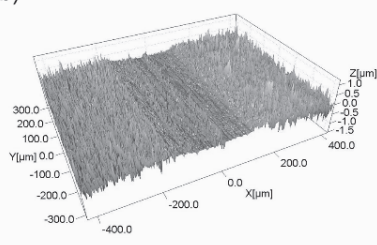

(c)

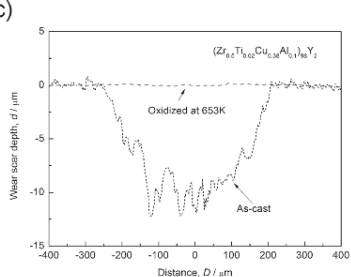

Fig. 2 The three-dimensional profiles of the wear scars on (a) the as-cast and (b) oxidized $\left(\mathrm{Zr}_{0.5} \mathrm{Ti}_{0.02} \mathrm{Cu}_{0.38} \mathrm{Al}_{0.1}\right)_{98} \mathrm{Y}_{2}$ and (c) two-dimensional profiles of the wear scars. 

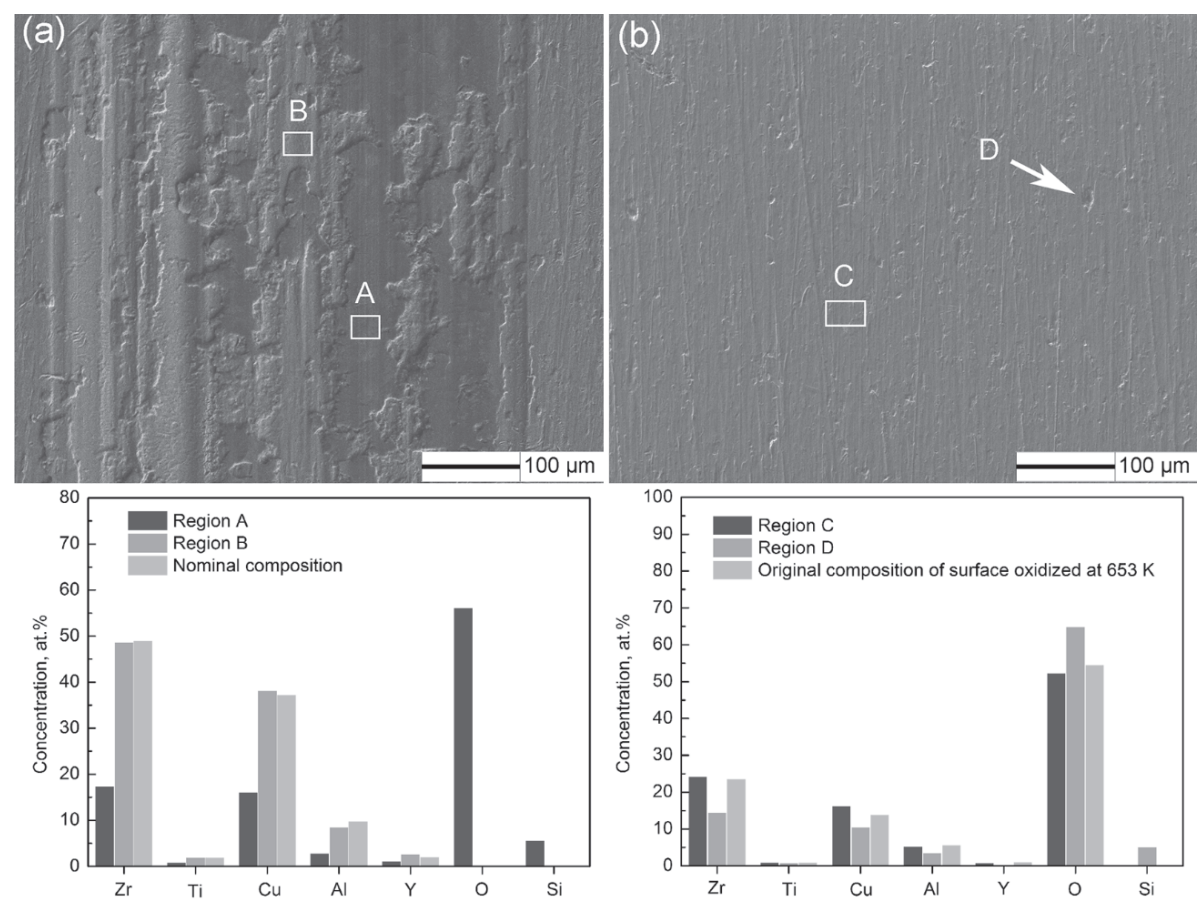

Fig. 3 The morphologies and EDS results of the wear scars on (a) the as-cast and (b) oxidized specimens.
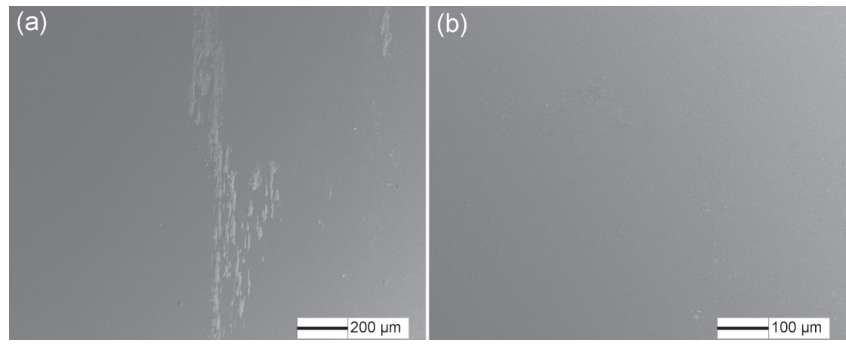

Fig. 4 The morphologies of the $\mathrm{Si}_{3} \mathrm{~N}_{4}$ counterparts sliding against (a) the as-cast and (b) oxidized specimens.

tion with the Zr-based BMG. In Fig. 4 (b), after sliding against the oxidized BMG, only a few tiny wear scars and almost no wear debris can be found on the surface of $\mathrm{Si}_{3} \mathrm{~N}_{4}$ sphere. The EDS result shows that the composition of the sphere remains $\mathrm{Si}$ and $\mathrm{N}$ elements. The Vickers hardness value of $\mathrm{Si}_{3} \mathrm{~N}_{4}$ is about $15 \mathrm{GPa}^{12)}$, much higher than the hardness of the as-cast $\left(\mathrm{Zr}_{0.5} \mathrm{Ti}_{0.02} \mathrm{Cu}_{0.38} \mathrm{Al}_{0.1}\right)_{98} \mathrm{Y}_{2}$ BMG (about 6.5 GPa), thus during sliding under this condition, wear mostly took place on the BMG. The hardness of $\mathrm{Si}_{3} \mathrm{~N}_{4}$ is also higher than that of the oxidized scale (about $11.3 \mathrm{GPa}$ ) on the $\mathrm{BMG}$, however, their hardness values are much closer than that between $\mathrm{Si}_{3} \mathrm{~N}_{4}$ and the BMG, besides, both the $\mathrm{Si}_{3} \mathrm{~N}_{4}$ and the scale are ceramics and they possess high hardness thus the wear are inconspicuous on them.

Based on the above results, the mechanism for the enhancement of wear resistance of the BMG by oxidation treatment can be explained as follows. After oxidation treatment, the surface of the BMG is covered by a layer of oxidized scale, therefore the friction pair is altered from metal-ceramic to ceramic-ceramic. The wear mechanism is thus different for the as-cast BMG and the oxidized BMG, for the as-cast one, the wear mechanism is a combination of abrasive wear and oxidative wear, while for the oxidized BMG, the predominant wear mechanism is abrasive wear. It is well known that ceramics possess good wear resistance ${ }^{18,19)}$ due to their high hardness, thus the change of friction pair and wear mechanism may lead to the enhancement of wear resistance of the BMG. Besides, a higher $H / E_{\mathrm{r}}$ ratio usually indicates better wear resistance ${ }^{20)}$, the scale on the oxidized BMG has a higher $H / E_{\mathrm{r}}$ ratio than the as-cast $\mathrm{BMG}$, as a result the wear resistance is improved.

\section{Conclusions}

The tribological behavior of the as-cast and surface oxidized $\left(\mathrm{Zr}_{0.5} \mathrm{Ti}_{0.02} \mathrm{Cu}_{0.38} \mathrm{Al}_{0.1}\right)_{98} \mathrm{Y}_{2} \mathrm{BMG}$ was studied by ballon-disc sliding tests. The results show that the wear resistance of the BMG could be remarkably improved by oxidation treatment. The improvement is mainly attributed to the formation of a layer of oxidized scale. The oxidation treatment could be an effective way to improve the surface properties of Zr-based BMGs and beneficial for many applications of Zrbased BMGs.

\section{Acknowledgment}

This work was financially supported by National Natural Science Foundation of China (Grant No. 51271008 and 51571005).

\section{REFERENCES}

1) A. Inoue and A. Takeuchi: Acta Mater. 59 (2011) 2243-2267.

2) J. Schroers, G. Kumar, T.M. Hodges, S. Chan and T.R. Kyriakides: JOM-J. Min. Met. Mat. S. 61 (2009) 21-29.

3) P.J. Blau: Wear 250 (2001) 431-434.

4) X.Y. Fu, T. Kasai, M.L. Falk and D.A. Rigney: Wear 250 (2001) 409419. 
5) G. Li, Y.Q. Wang, L.M. Wang, Y.P. Gao, R.J. Zhang, Z.J. Zhan, L.L. Sun, J. Zhang and W.K. Wang: J. Mater. Res. 17 (2002) 1877-1880.

6) T. Gloriant: J. Non-Cryst. Solids 316 (2003) 96-103.

7) M.Z. Ma, R.P. Liu, Y. Xiao, D.C. Lou, L. Liu, Q. Wang and W.K. Wang: Mater. Sci. Eng. A 386 (2004) 326-330.

8) H.W. Jin, R. Ayer, J.Y. Koo and R.R.U. Ramamurty: J. Mater. Res. 22 (2007) 264-273.

9) Z. Parlar, M. Bakkal and A.J. Shih: Intermetallics 16 (2008) 34-41.

10) M.Z. Ma, H.T. Zong, H.Y. Wang, W.G. Zhang, A.J. Song, S.X. Liang, Q. Wang, X.Y. Zhang, Q. Jing and G. Li: Mater. Lett. 62 (2008) 4348 4350 .

11) J. Kong, D. Xiong, J. Li, Q. Yuan and R. Tyagi: Tribol. Lett. 35 (2009) $151-158$.

12) Y. Wang, L.L. Shi, D.L. Duan, S. Li and J. Xu: Mater. Sci. Eng. C 37
(2014) 292-304.

13) N. Hua, Z. Zheng, H. Fang, X. Ye, C. Lin, G. Li, W. Wang, W. Chen and T. Zhang: J. Non-Cryst. Solids 426 (2015) 63-71.

14) H. Wu, I. Baker, Y. Liu, X. Wu and P.R. Munroe: Intermetallics 25 (2012) 115-125.

15) H. Dong and T. Bell: Wear 238 (2000) 131-137.

16) F. Borgioli, E. Galvanetto, F. Iozzelli and G. Pradelli: Mater. Lett. 59 (2005) 2159-2162.

17) K. Zhou, Y. Liu, S. Pang and T. Zhang: J. Alloy. Compd. 656 (2016) 389-394.

18) C.S. Yust and F.J. Carignan: Tribol. Trans. 28 (1985) 245-252.

19) M.S. Suh, Y.H. Chae and S.S. Kim: Wear 264 (2008) 800-806.

20) A. Leyland and A. Matthews: Wear 246 (2000) 1-11. 